\begin{tabular}{|ccc}
\hline Sournals & $\begin{array}{c}\text { INTERNATIONAL JOURNAL OF } \\
\text { ORGANIZATIONAL LEADERSHIP }\end{array}$ & $\begin{array}{c}\text { INDUSTRIAL } \\
\text { MANAGEMENT } \\
\text { INSTITUTE }\end{array}$ \\
\hline \hline
\end{tabular}

\title{
Mechanisms of monitoring efficiency of the state executive authorities: Theory and practice
}

\author{
Mikhail Ivanov \\ Samara State Academy of Social Sciences and Humanities
}

\section{Keywords: \\ State and municipal administration, Evaluating performance Efficiency, Performance efficiency monitoring}

Received

26 November 2015

Received in revised form 16 February 2016

Accepted

28 February 2016

Correspondence:

i3002@yandex.ru

\begin{abstract}
The paper presents results of studying mechanisms applicable to evaluating performance efficiency of the executive authorities in one of the Russian Federation regions - Samara oblast - involved in organizing delivery of social services, which includes review of normative documents containing methodological deliberation and guidelines on conducting the monitoring. The indicators, which use in monitoring, shall be compatible with the following requirements: in calculating the indicators numerical values, applicable shall be the data of governmental statistical accounting or information collected in the course of carrying out official evaluation procedures; in calculating the indicators, applicable shall be easily verifiable information collected as a result of responses of the social services territorial management entities to inquiries of higher-level authorities; the use of indicators shall not imply interpretation of the collected information. It also important to substitute indicators that require additional interpretation for indicators that are supposed to demonstrate the immediate result of the public authority body's activity; such indicators have to be able of impacting the public administration body's activity in the event of using them in the monitoring patterns.
\end{abstract}

(C)AIMI Journals

\section{Introduction}

One of the usual run of things in the majority of civilized states is availability of a large-scale public sector. It exists with the purpose of compensating externalities that are indispensable and inevitable in any economics. Public services in the sphere of education, healthcare, culture, social security are delivered by the state and municipal institutions or by private organizations for account of nongovernmental funds.

Russia is not an exception in that respect. By virtue of traditions, in the majority of cases, educational, healthcare and other socially relevant benefits are delivered by the state or municipal institutions for account of nongovernmental funds. Distribution of these funds is the 
jurisdiction of territorial bodies of public administrations. Their responsibility area also includes establishing, liquidation and territorial deployment of institutions that produce the corresponding public benefits. This being so, the main goal of these bodies is ensuring availability of high-quality services for the residents across the respective territories - given efficient use of resources.

Furthermore, the current agenda includes evaluation of the degree of achieving the goals. The first aspect of this evaluation - understanding the results and effects of producing public benefits - has been altogether covered in academic publications. Generally speaking, this task has been completed: relevant evaluation techniques are there, indicators enabling evaluation of performance efficiency of individual institutions-producers of public benefits as well as territorial systems of producing public benefits are successfully employed. These indicators reflect both performance results of the corresponding territorial systems and the externalities.

Another evaluation aspect emphasizes evaluation of the performance efficiency of the public administration bodies, evaluation of their activity's immediate result. In this context, it is not always clear - what should be the subject-matter of the evaluation and how it should proceed. That sort of ambiguity often results is using the same indicators in evaluating the public administration bodies and the territorial systems with regard to producing public benefits in general.

\section{Research Design}

Efficiency evaluation of the public sector and the public administration's territorial bodies remains in the focus of attention of specialists from different countries.

One of the research directions is linked to defining and classifying externalities of various kinds. Major contribution in developing the social impacts theory has been made by A. Atkinson and J. Stiglitz (Atkinson \& Stiglitz, 1980), E. Mishan (Mishan, 1984), R. Musgrave (Musgrave, 1989), E. Gramlich (Gramlich, 1981), contemporary scientists B. Hansen and P. Dolan [Hansen \& Dolan, 2002), however the notion 'social impact' remains arbitrary and ambiguous. F. Vankley defines the social impact as 'the kind, form and content of the given social change' (Adamenko, Gerashenko, Gorodnova, 2010). Simultaneously, the author of the monograph emphasizes complexity of exposing social impacts. In his judgment, socially efficient is a phenomenon that is a direct consequence or result of implementing the budget program; it is worthwhile considering improvement of the life quality (social welfare) as the key indicator of the social impact and not the life level; social impact is in its capacity as such only if the community perceives it as a social impact attributing usefulness to it.

A. Williams and I. Giardina define the phenomenon under consideration (i.e., social impact) as social-cultural changes in the social status, which can be negative or positive, directly or indirectly being consequences of activities, implementation of a project or a program (Williams \& Giardina, 1993). Availability of externalities in form of positive social impacts (from the point of view of the state) motivates the government to produce certain services.

Efficiency evaluation with regard to the public sector is equally in the limelight of researchers. Specifically, in the educational management theory (Hanushek, 1986, 1987), (Becker, 1960, 1964), (Coleman, 1966, 1981, 1987), (King, 1983, 1989), (MacPhail-Wilcox, 1986) two aspects of efficiency are considered - external and internal. The external efficiency 
reflects contribution of limited resources (invested into the sphere of education) to the economic growth. The internal efficiency is linked to distribution of resources inside the educational institutions with the purpose of maximizing results (progress in studies, development of practical skills as well as the required students' behavior patterns).

A number of publications contain description of the experience of evaluating efficiency of the public administration bodies. Thus, in the USA evaluation of the public administration quality (evaluation of financial management, HR management, IT and capital expenditures evaluation) is carried out under the GPP (Government Performance Project) technique, in which case financing is delivered from private sources. This methodology - among other things - enables horizontal comparisons of the states and counties as per the following criteria: efficient information technologies management; efficient capital expenditures management (long-term format of using capital expenditures, permanent monitoring and control of capital investments efficiency); management focusing on result (using technologies of budgeting as per result; using and improving performance effectiveness indicators; proper organization of tenders and public auctions; involving citizens in management).

In Sweden, the quality rating of executive authorities bodies' financial management is used for evaluating the financial management quality; this technique is based on the National Financial Office methodological approach. The evaluation results are used to consider the spending units' applications for the next fiscal year.

The public administration efficiency evaluation in Belgium implies analysis of statutory enactments and administrative procedures (with a view to expose excessive administrative load) and monitoring the draft laws. As an integrated characteristic of the public administration system status, the so-called 'Kafka Index' is used, which reflects the bureaucracy inefficiency level. Higher values of the Index constitute grounds for revision of the existing administrative procedures and the corresponding laws and regulations (Klimenko, 2007).

This research is based on the author's concept of developing the public administration body's activity monitoring in the spheres of education, healthcare, social welfare, culture, mass physical culture and sports).

Firstly, we proceed from our own understanding of the public administration body's functions. They consist not in managing one single institution being a producer of public benefits; the reason is that each of such institutions has got its own management. The public administration body manages the territorial system of producing public benefits in most general terms. It goes on like that because the respective public administration body resembles a holding's parent company as per its functions: institutionally, the body is separated from the production divisions; it does not possess its own production capacities, it is not involved in any production activity. The main functions of that body are: coming up with the mission statement for public benefits producers as well as ensuring actualization of the mission by various resources (financial, material, labor, informational, organizational), which includes setting the 'rules of game' to be understood as the ways of distributing the resources inside the territorial system. Proceeding from the above, we adopt the purpose-specific approach to understanding the public administration body's efficiency; this approach implies application of only those indicators that reflect performing the body's functions linked to setting goals for the institutions-producers of public benefits and ensuring implementation of these goals via 
relevant resources and by modifying the activated management mechanisms (mechanisms of financing and interplay with the external environment entities as well as optimization of the institutions-producers of public benefits networks structure; mechanisms of HR development and mechanisms of controlling and monitoring the territorial public benefits production system).

Secondly, we consider monitoring as a means of influencing the public administration body's activity by presetting indicators (which are designed to demonstrate direct results of the respective body's activity) not after the collected information analysis as a result of corrective impact but presetting indicators to which the public administration's activity is 'adjusted' [reference to me]. To make this happen, the indicators shall be compatible with the following requirements:

- In calculating the indicators numerical values, applicable shall be the data of governmental statistical accounting or information collected in the course of carrying out official evaluation procedures;

- In calculating the indicators, applicable shall be easily verifiable information collected as a result of responses of the social services territorial management entities to inquiries of higherlevel authorities;

- The use of indicators shall not imply interpretation of the collected information.

Practices of shaping the public administration bodies' performance efficiency monitoring have been reviewed on the basis of Samara oblast (region) facts and figures. For this purpose, annual reports by the Samara oblast ministries (education and science; healthcare and social development; culture; sports, tourism and youth policy) were studied.

These reports contain strategic and tactical goals of these public administration bodies' activity as well as indicators proposed for evaluating performance efficiency of the ministries over the calendar year.

\section{Empirical Results}

In our opinion, the common imperfection of these reports is that the ministries' activity goals are laid down so loosely that it is often impossible to understand - what kinds of results have to be obtained by the ministry. In the majority of cases, the goals are given in form of postponed effects, which have very weak relation to the public administration body's activity results and to the public benefits production outcomes. Our topic to be studied was the set of indicators for evaluating the ministries' activity; the corresponding analysis was performed from the perspective of the above-described concept.

For this reason, the analysis resulted in immediate 'screening out' those indicators that implied additional meanings interpretation, because they did not set any benchmarks for the territorial-branch complexes' activity and are unable of ensuring preventive impact onto the managerial bodies' activity. In the ranks of indicators that set benchmarks for the territorialbranch complexes' activity some were of interest for us (from the point of view of targeting changes in the managerial body's activity), while others reflected social impacts and results of activity of the institutions providing public benefits. Some cases showed evidently erroneous indicators (focusing on changes in the managerial objects, impact onto which was outside the limits of the managerial body's jurisdiction). On each occasion, consideration was given to the 
indicators' quality from the viewpoint of their verification.

Analysis of annual reports submitted by the Ministry for Education and Science of Samara oblast showed that of all the indicators only $37 \%$ promote changes in the managerial body's activity (Table 1).

Table 1

Structure of Performance Efficiency Indicators Ministry for Education and Science of Samara Oblast

\begin{tabular}{|c|c|c|}
\hline Indicator type & Indicator share, $\%$ & Of which - verifiable, $\%$ \\
\hline Indicators implying additional interpretation of meanings & 57 & 100 \\
\hline $\begin{array}{l}\text { Indicators setting benchmarks for the territorial-branch complexes' } \\
\text { activity including: }\end{array}$ & 43 & 84 \\
\hline - targeting changes in the managerial body's activity & 37 & 96 \\
\hline - reflecting social impacts & 2 & 0 \\
\hline - reflecting results of activity of institutions providing public benefits & 4 & 0 \\
\hline $\begin{array}{l}\text { Indicators focusing on changes in the managerial objects, impact onto } \\
\text { which is outside the limits of the managerial body's jurisdiction }\end{array}$ & 1 & 100 \\
\hline
\end{tabular}

Specifically, the indicator 'Expenditures of the consolidated budget of the federation constituent entity for budget-funded services delivered by nongovernmental institutions in the sphere of education and science' guides the Ministry for Education and Science to engage the mechanism of budget-specific funding of nongovernmental general-education institutions holding state accreditation.

The indicator 'Share of unemployed graduates of elementary vocational-training institutions registered at the employment office vs. the total number of registered unemployed' promotes modification of the mechanisms of interrelations of the social services territorial systems and the external environment entities (including the ultimate social services consumers) because this indicator stirs up the Ministry's activity as for establishing contacts with the employers' associations regarding exploration and forecasting the labor market status - with the purpose of bringing into accord the market status and demands and the offered educational programs as well as improving the specialists' training techniques. In addition, this indicator assists heads of institutions within the relevant jurisdiction of elementary vocational training in setting feasible tasks.

Quite a few indicators target measures as to improving the network of institutions within the relevant jurisdiction. Thus, the indicator 'Share of accredited educational institutions vs. their total number' obligates the Ministry for Education and Science to ensure adequate services quality across the region's territory in a maximum possible number of educational institutions, since successful passing of state accreditation reflects the educational services normative quality in the accredited institution.

Further, the indicator 'Number of state educational institutions of elementary vocational training in Samara oblast, the premises of which are in unsafe condition or require major repair' guides the Ministry to decrease the number of unsafe buildings.

Generally speaking, a small number of indicators is used to orient the executive authorities' bodies towards modification of the HR development mechanisms. For example, the indicator 'Share of job opportunities vs. total number of educators of the region's educational 
institutions' guides the Ministry to launch programs stimulating inflow of trained personnel into the educational system and to take measures as to filling the corresponding positions (including purpose-specific enrollment to the secondary and higher occupational-training institutions combined with setting appropriate goals for the heads of institutions within the Ministry's jurisdiction).

The indicator referred to as 'Share of the vocational-training system employees who has been additionally trained vs. the total number of the employees in the branch' guides the Ministry to ensure regular improvement of occupational skills among the pedagogical and managerial staff within the vocational education system by means of implementing relevant programs at the oblast (regional) level as well as setting appropriate tasks for the heads of institutions within the Ministry's jurisdiction.

'Share of teachers at state (municipal) general-education institutions having pedagogical employment history up to 5 years vs. the total number of teachers at state (municipal) generaleducation institutions' - this indicator makes emphasis on setting relevant tasks for the heads of the educational institutions covered by the Ministry's jurisdiction and engaging programs of developing HR.

The indicators known as 'Provision of secondary-school students with hot meals' and 'Share of children at the age of 5-15 years not engaged in the main general-education programs vs. total number of children of this age group' promote development of the corresponding control procedures and setting appropriate tasks for the educational institutions heads.

Analysis of the Ministry for Healthcare and Social Development annual reports showed that the following indicator types are used in evaluation (Table 2).

Table 2

Structure of Performance Efficiency Indicators Ministry for Healthcare and Social Development of Samara Oblast

\begin{tabular}{lcc}
\hline Indicator type & Indicator share, \% & Of which - verifiable, \% \\
\hline Indicators implying additional interpretation of meanings & 55 \\
Indicators setting benchmarks for the territorial-branch complexes & 45 & 97 \\
activity including: & 21 \\
- targeting changes in the managerial body's activity & 23 \\
- reflecting social impacts & 1 & 94 \\
- reflecting results of activity of institutions providing public benefits & \\
Indicators focusing on changes in the managerial objects, impact \\
onto which is outside the limits of the managerial body's jurisdiction
\end{tabular}

In particular, the following indicators are worthwhile mentioning in terms of targeting changes in the rules of financing the healthcare system.

The indicator 'Average nominal monthly salary paid to the doctors of state (municipal) healthcare institutions' guides the Ministry for Healthcare and Social Development to introduce changes in the doctors' labor remuneration mechanism and to set appropriate tasks for the heads of medical institutions under the Ministry's jurisdiction designed to lead to increase of the average monthly paid salary.

The indicator 'Deficit of financial provision of the territorial program of state guarantees as 
to delivery of free medical aid to the Russian Federation citizens is a tool at the disposal of the Ministry for Healthcare and Social Development to improve financing of the healthcare services delivery and finally - to liquidation of the deficit.

The indicator 'Number of state (municipal) healthcare institutions transited predominantly to the one-channel financing' guides the Ministry to undertake relevant steps in that respect.

The indicator 'Number of state (municipal) healthcare institutions converted to the new (branch-specific) labor remuneration system targeting the ultimate result' makes it possible to impact the Ministry's activity in terms of increasing the number of institutions where the personnel labor remuneration is calculated in compliance with the new rules: connecting the salary with the results of the job activities.

The indicator 'Number of state (municipal) healthcare institutions financed after considering the activity results on the basis of the capitation standard rate per assigned number of residents' enables guiding the Ministry's activity to developing quasi-markets of healthcare services, thus ensuring connection between their consumption volume and the financing volume.

'Number of state (municipal) healthcare institutions financed as per finalized case' - this indicator forces the Ministry for Healthcare and Social Development to change the mechanism of the medical aid delivery financing in terms of financing on the basis of the ultimate result and not just by fact of the institution's operation.

The indicator 'Annual average bed utilization' guides the Ministry to set tasks for the heads of institutions within its jurisdiction as to increasing efficiency of using the bedspace and to take structural decisions including opening, liquidation and reorganizing the institutions having bedspace at their disposal as well as the structural divisions of such institutions.

The next indicator 'Number of state (municipal) healthcare institutions, the premises of which are in unsafe condition or require major repair' guides the Ministry to participate in the budget-development process, which basically involves allocation of resources for the capital repair and civil engineering purposes as well as setting tasks for the healthcare institutions' heads within the jurisdiction of the Ministry; the final goal is to decrease the number of such institutions, ideally - to eliminate them.

The indicator 'Share of state (municipal) institutions' guides the public administration body to engage appropriate control procedures and to set corresponding tasks for the institutions' heads.

The indicators structure employed for the performance efficiency evaluation concerning the Ministry for Culture of Samara oblast is presented in Table 3.

A fairly large number of indicators guide the public administration body to change the rules of financing the cultural sector. Thus, the indicator 'Ratio of the monthly average paid salary of the state (municipal) institutions of culture and art vs. the average monthly labor remuneration of the workers employed in the regional economics' as well as the indicator 'Average monthly paid salary of the employees working in the state (municipal) institutions of culture' guides the Ministry to change the mechanisms of labor remuneration in the cultural sector and set relevant tasks for the heads of institutions under the jurisdiction of the Ministry; ultimately it results in growth of the average monthly labor remuneration. 
Structure of Performance Efficiency Indicators Ministry for Culture of Samara Oblast

\begin{tabular}{|c|c|c|}
\hline Indicator type & Indicator share, $\%$ & Of which - verifiable, $\%$ \\
\hline Indicators implying additional interpretation of meanings & 33 & 43 \\
\hline $\begin{array}{l}\text { Indicators setting benchmarks for the territorial-branch complexes' } \\
\text { activity including: }\end{array}$ & 67 & 50 \\
\hline - targeting changes in the managerial body's activity & 33 & 100 \\
\hline - reflecting social impacts & 5 & 0 \\
\hline - reflecting results of activity of institutions providing public benefits & 29 & 0 \\
\hline $\begin{array}{l}\text { Indicators focusing on changes in the managerial objects, impact onto } \\
\text { which is outside the limits of the managerial body's jurisdiction }\end{array}$ & 0 & - \\
\hline
\end{tabular}

Similar is the operation of the indicator 'Share of cultural institutions' premises that are in satisfactory state vs. total number of premises occupied by institutions of culture and art'; this indicator guides the Ministry for Culture to maintain in satisfactory state the buildings used by the cultural institutions as well as to set relevant tasks for the heads cultural institutions within the Ministry's jurisdiction.

Generally, some few applied indicators promote changes in the control mechanisms in the branch-related systems explicitly sorting out the control objects and in certain cases the control tools as well. Specifically, 'Number of new books delivered to public libraries per 1 thou of the residents', 'Share of the residents participating in charged cultural-leisure events conducted by state (municipal) institutions of culture', etc. focus on engaging relevant control procedures as well as setting tasks for the cultural institutions heads.

Below (in Table 4) please find the results of the performance efficiency indicators with regard to the Ministry for Sports of Samara oblast.

Table 4

Structure of Performance Efficiency Indicators Ministry for Sports of Samara Oblast

\begin{tabular}{lcc}
\hline Indicator type & Indicator share, $\%$ & Of which - verifiable, \% \\
\hline $\begin{array}{l}\text { Indicators implying additional interpretation of meanings } \\
\text { Indicators setting benchmarks for the territorial-branch complexes' }\end{array}$ & 40 & 100 \\
activity including: & 60 & 83 \\
- targeting changes in the managerial body's activity & 15 & 100 \\
- reflecting social impacts & 25 & 20 \\
- reflecting results of activity of institutions providing public benefits & 20 & 100 \\
$\begin{array}{l}\text { Indicators focusing on changes in the managerial objects, impact onto } \\
\text { which is outside the limits of the managerial body's jurisdiction }\end{array}$ & 0 & -
\end{tabular}

The applicable monitoring systems are not deprived of bottlenecks. Specifically, in evaluating the Samara oblast executive authorities' bodies that run the state policy in the social services sphere, several employed indicators force these bodies to carry out actions outside their scope of reference. Thus, there exists an indicator commonly referred to as 'Share of higher-qualification staff within the faculty of state-run universities operating in Samara oblast' (Ministry for Education and Science). This being so, the Ministry lacks any 'leverage' over the 
state, municipal and non-state universities and their branches - even in terms of setting tasks for their heads.

In evaluating performance efficiency of the Samara oblast executive authorities' bodies implementing the state policy in the social services realm, it is conventional to use indicators, the name of which does not give sufficient information as to what specific mechanisms they are supposed to promote; neither they provide assistance in understanding what should be modified in the indicator's value to demonstrate positive result. Here are examples of such indicators. 'Number of graduates who passed the Uniform State Exam in mathematics (the value of this indicator changes in conjunction with the number of persons taking the exam in the current year). The value of the indicator 'Number of state educational institutions of elementary vocational training in Samara oblast' is contingent on the results of the Ministry for Education and Science activity and can fluctuate this or other way - depending on the managerial decisions taken, it is next to impossible to reveal the positive direction of the value's changes.

In evaluating performance efficiency of the Samara oblast public administration bodies in the healthcare realm, indicators were used, where the wording prevents the persons concerned from understanding - modification of exactly which specific mechanisms they promote; neither is it clear - in which direction the indicator's value should be changed to obtain positive outcome. Thus, the value of the indicator known as 'Cost of one volume unit of the in-patient aid delivered (actual value)' depends on the specific medical case, disease patterns as well as on the resource-intensiveness of the treatment, but not on the approaches selected by the Ministry for Healthcare and Social Development or municipal institutions of social services. The indicator supplied with the title 'Number of medical doctors per 10000 residents' can either increase or decrease, although it is unclear - what is the impact of the specific population on the degree of solving tactical tasks by the Ministry for Healthcare and Social Development.

Some of the data required for calculating efficiency evaluation indicators is not reflected in the state statistical reporting, at the same time they are not easily verifiable. In particular, 'The residents' satisfaction with the medical aid' is proposed to be measured via public opinion surveys.

It is not uncommon that the performance efficiency evaluation is carried out involving indicators that are absolutely inappropriate for the purpose of understanding the degree of contribution made to the social impacts by the corresponding administrative body. The following indicators can be classified as inappropriate: 'Number of medals won by the Samara oblast athletes' (Ministry for Sports), indicators of the life quality - 'Infant mortality (per 1 thou live births)', 'Population mortality (by age groups)', 'Population of employable age mortality due to external causes', 'Population mortality as a result of traffic accidents'.

Values of such indicators as 'Share of e-catalogues in the total volume of catalogues of museum items and museum collections of the Museum Item Pool of the Russian Federation situated in Samara oblast', 'Number of socially vulnerable citizens and children involved into the social-cultural activity of museums and theater-concert institutions', 'Number of interregional and international projects implemented in the cultural sphere', 'Number of amateur folk art groups being active under the aegis of culture-leisure institutions' require additional interpretation. The benchmark data to be used for calculating the above indicators can easily become subject of manipulation. 
The value of some indicators is directly dependent on the results of the relevant ministry performance and can significantly vary in connection with the managerial decisions taken, but it is rather challenging to discover the positive direction of the changes. Here is a couple of examples of such indicators: 'Expenditures of the Russian Federation constituent entity's consolidated budget for developing the sphere of culture: totally, per 1 resident', 'Number of sport titles awarded'.

The indicators 'Satisfaction of the residents with the conditions of going in for physical culture and sports', 'Share of the residents systematically going in for physical culture and sports' appear to be difficult to verify.

The overall indicators structure for evaluation of any public administration bodies is presented in Table 5 below.

Table 5

Structure of Performance Efficiency Indicators Public Administration Bodies

\begin{tabular}{lcc}
\hline Indicator type & Indicator share, $\%$ & Of which - verifiable, $\%$ \\
\hline Indicators implying additional interpretation of meanings & 52.8 & 95.1 \\
$\begin{array}{l}\text { Indicators setting benchmarks for the territorial-branch complexes' } \\
\text { activity including: }\end{array}$ & 46.8 & 83.5 \\
- targeting changes in the managerial body's activity & 30.5 & 97.1 \\
- reflecting social impacts & 10.3 & 66.7 \\
- reflecting results of activity of institutions providing public benefits & 6.0 & 35.7 \\
Indicators focusing on changes in the managerial objects, impact onto & 0.4 & 100 \\
which is outside the limits of the managerial body's jurisdiction & 100 & 89.7 \\
Total & & \\
\hline
\end{tabular}

\section{Some Considerations on the Research Results}

In summary, in accordance with the findings of the analysis of indicators used for evaluating the performance efficiency of the Samara oblast executive authorities' bodies, which implement the state policy in the public services sphere, one can make the conclusion that $52.8 \%$ of the mentioned indicators imply additional interpretation of their values, i.e., they do not specify the target orientation for activities of the corresponding territorial-branch complexes; of all the indicators in one way or another specifying benchmarks for the complexes' activity - totally in the social services sphere $-69.5 \%$ do not reflect the direct results of the managerial bodies' activity (this being so, 10.3\% account for indicators reflecting social impacts, while $6 \%$ - for indicators reflecting activity of the institutions delivering social services), $0.4 \%$ promote changes in the objects of management, which exceeds the limits of the departments' scope of responsibility, and only 30.5\% promote changes of the specific mechanisms; moreover, the source data for calculating $10.3 \%$ of all the indicators appears to be non-verifiable.

In this connection, it appears to be necessary to significantly decrease the number of the indicators, which is necessary for singling out the priority fields of changes in the public administration's activity. It is equally necessary to eliminate the 'multidirectional' indicators those that guide the public administration body to undertake oppositely directed actions.

It also appears important to substitute indicators that require additional interpretation for 
indicators that are supposed to demonstrate the immediate result of the public authority body's activity; such indicators have to be able of impacting the public administration body's activity in the event of using them in the monitoring patterns.

\section{Acknowledgements}

The author wishes to acknowledge Prof. Lev Fishman, Samara State Academy of Social Sciences and Humanities, for helpful comments made on an earlier version of this paper.

\section{References}

Atkinson, A., Stiglitz, J. (1980). Lectures on public economics. New York: McGraw-Hill.

Becker, G.S. (1964). Human capital: A theoretical and empirical analysis with special reference to education. New York: National Bureau of Economic Research.

Becker, G.S. (1960). Underinvestment in college education? American Economics Review (Papers and proceedings), 50, $232-$ 240.

Coleman, J.S. (1966). Equality of educational opportunity. Washington, DC: U.S. Government Printing Office.

Coleman, J.S., Hoffer, T. (1987). Public and private high schools: The impact of communities. New York: Basic Books.

Coleman, J.S., Hoffer, T., Kligore, S. (1981). Public and private high schools. Washington, DC: National Center for Education Statistics.

Adamenko, A.A., Gerashenko, I.P., Gorodnova, N.V. (2010). Finansovoje upravlenie razvitiem ekonomicheskih sistem. Novosibirsk

Gramlich, E. (1981). Benefit-cost analysis of government programs. Englewood Cliffs. - NJ: Prentice Hall.

Hanushek, E.A. (1987). Education production functions. Oxford, England: Pergamon Press.

Hanushek, E.A. (1986). The economics of schooling: Production and efficiency in public schools. Journal of Economic Literature, 24, 48-54.

King, R.A. (1983). Equalization in New Mexico school finance. Journal of Education Finance, 9, 154-162.

Klimenko, A.V. (2007). Ispolnitelnaja vlast kak objekt monitoringa i otsenki. Problemy sovremennogo gosudarstvennogo upravlenija $v$ Rossii, 3(8), 116-120.

MacPhail-Wilcox, B., King, R.A. (1986). Production functions revisited in the context of educational reform. Journal of Educational Finance, 12, 341-350.

Mishan, E.J. (1984). Cost - benefit analysis. London: George Allen \& Unwin Ltd.

Musgrave, R.A., Musgrave, P.B. (1989). Public finance in theory and practice. New York: McGraw-Hill.

Williams, A. (1993). Efficiency in the Public Sector: the theory and practice of cost-benefit. Cambridge: University Press. 